\title{
Neurogenic bladder dysfunction revisited; the risk on upper urinary tracts
}

Volume I Issue 6 - 2014

\section{Tariq O Abbas}

Department of Paediatric Urology, Birmingham Children Hospital NHS Trust, UK

Abbreviations: NBD, neurogenic bladder dysfunction; CNS, central nervous system; DSD, detrusor sphincter dyssynergia; SBO, spina bifida occulta

\section{Editorial}

The most common cause of Neurogenic Bladder Dysfunction (NBD) is meningomyelocele. However, NBD can result to CNS at any level. Other reasons behind Neurogenic Bladder Dysfunction include spina bifida occulta (SBO), sacral agenesis, lipomeningocele and tethered cord. ${ }^{1-4}$ The average worldwide incidence of spina bifida is 1 case per 1000 births, but marked geographic variations occur. The chance of having a sibling with the same condition is about $3-5 \%$ if the myelomeningocele is present in one child in a family. Folic acid deficiency appears to increase the incidence of having a child with spinal dysraphism. ${ }^{5}$

The upper urinary tract at birth in most newborns with spina bifida is normal. Without adequate management, the majority will develop bladder-wall and renal changes. ${ }^{6,7}$ Escalating renal damage is due to high detrusor pressures both during the filling and voiding phases of bladder cycle as well as detrusor sphincter dyssynergia (DSD). ${ }^{4-11}$ Recurrent urinary infections happens in many patients with NBD, which can increase the risk for renal impairment. NBD-related kidney impairment is considered the cause of major long-term morbidity in these patients like hypertension. ${ }^{6-8}$

NBD must be treated as soon as possible after birth following closure of the back lesion to prevent renal damage. ${ }^{9,10}$ Considerable progress has been made in the management of children with the NBD over the past few decades. ${ }^{1,2,6,11-13}$ These advances are primarily due to the introduction of clean intermittent catheterization (CIC), discovery of newer medications as well as the engagement of urodynamics study during infancy. ${ }^{11,14-16}$ The use of a multidisciplinary team management approach with records and electronic data transmission have made it possible to both safely and remarkably protect the upper urinary tract, and improve the patient's outcome and quality of life. This multidisciplinary team includes pediatricians, urologist, neurosurgeon, orthopaedic surgeons, nephrologist, and physical medicine and rehabilitation workers. ${ }^{17}$

\section{Acknowledgments}

None.

\section{Conflicts of interest}

Author declares there are no conflicts of interest.

\section{Funding}

None.

\begin{abstract}
Correspondence: Tariq O Abbas, Department of Paediatric Urology, Birmingham Children Hospital NHS Trust, Steel house Lane, B4 6NH, Birmingham, UK, Tel 447000000000, Email Tariq.Abbas@bch.nhs.uk
\end{abstract}

Received: November 05, 2014 | Published: November II, 2014

\section{References}

1. Mourtzinos A, Stoffel JT. Management goals for the spina bifida neurogenic bladder: A review from infancy to adulthood. Urol Clin North Am. 2010;37(4):527-535.

2. Frimberger D, Cheng E, Kropp BP. The current management of the neurogenic bladder in children with spina bifida. Pediatr Clin North Am. 2012;59(4):757-767.

3. Amarante MA, Shrensel JA, Tomei KL, et al. Management of urological dysfunction in pediatric patients with spinal dysraphism: Review of the literature. Neurosurg Focus. 2012;33(4):E4.

4. Bauer SB. Neurogenic bladder: Etiology and assessment. Pediatr Nephrol. 2008;23(4):541-551.

5. Rothenberg SP, da Costa MP, Sequeira JM, et al. Autoantibodies against folate receptors in women with a pregnancy complicated by a neuraltube defect. N Engl J Med. 2004;350(2):134-142.

6. Shin M, Kucik JE, Siffel C, et al. Improved survival among children with spina bifida in the United States. J Pediatr. 2012;161(6):1132-1137.

7. Satar N, Bauer SB, Scott RM, et al. Late effects of early surgery on lipoma and lipomeningocele in children less than 1 year old. $J$ Urol . 1997;157(4):1434-1437.

8. Kari JA. Neuropathic bladder as a cause of chronic renal failure in children in developing countries. Pediatr Nephrol. 2006;21(4):517-520.

9. Filler G, Gharib M, Casier S, et al. Prevention of chronic kidney disease in spina bifida. Int Urol Nephrol. 2012;44(3):817-827.

10. Lehnert T, Weisser M, Till H, et al. The effects of long-term medical treatment combined with clean intermittent catheterization in children with neurogenic detrusor over activity. Int Urol Nephrol . 2012;44(2):335-341.

11. Verpoorten C, Buyse GM. The neurogenic bladder: Medical treatment. Pediatr Nephrol . 2008;23(5):717-725. 
12. Himsl KK, Hurwitz RS. Pediatric urinary incontinence. Urol Clin North Am. 1991;18(2):283-293.

13. Edelstein RA, Bauer SB, Kelly MD, et al. The long-term urological response of neonates with myelodysplasia treated proactively with intermittent catheterization and anticholinergic therapy. $J$ Urol. 1995;154(4):1500-1504.

14. Lavallee LT, Leonard MP, Dubois C, et al. Urodynamic testing - Is it a useful tool in the management of children with cutaneous stigmata of occult spinal dysraphism? J Urol . 2013;189(2): 678-683.
15. Drzewiecki BA, Bauer SB. Urodynamic testing in children: Indications, technique, interpretation and significance. $J$ Urol. 2011;186(4):1190-1197.

16. Bauer SB, Hallett $M$, Khoshbin S, et al. Predictive value of urodynamic evaluation in newborns with myelodysplasia. JAMA. 1984;252(5):650-652.

17. Sarica K, Erbagci A, Yagci F, et al. Multidisciplinary evaluation of occult spinal dysraphism in 47 children. Scand J Urol Nephrol. 2003;37(4):329-334. 